\title{
Using fuzzy cognitive mapping as a participatory approach to analyze change, preferred states, and perceived resilience of social-ecological systems
}

\author{
$\underline{\text { Steven A. Grav }}^{1}, \underline{\text { Stefan Grav }}^{2}, \underline{\text { Jean Luc De Kok }}^{3}, \underline{\text { Ariella E. R. Helfgott }}^{4}$, Barry O'Dwver $^{2}, \underline{\text { Rebecca Jordan }}^{5}$ and Angela Nyaki $^{6}$
}

\begin{abstract}
There is a growing interest in the use of fuzzy cognitive mapping (FCM) as a participatory method for understanding social-ecological systems (SESs). In recent years, FCM has been used in a diverse set of contexts ranging from fisheries management to agricultural development, in an effort to generate transparent graphical models of complex systems that are useful for decision making, illuminate the core presumptions of environmental stakeholders, and structure environmental problems for scenario development. This increase in popularity is because of FCM's bottom-up approach and its ability to incorporate a range of individual, community-level, and expert knowledge into an accessible and standardized format. Although there has been an increase in the use of FCM as an environmental planning and learning tool, limited progress has been made with regard to the method's relationship to existing resilience frameworks and how the use of FCM compares with other participatory modeling/approaches available. Using case study data developed from community-driven models of the bushmeat trade in Tanzania, we examine the usefulness of FCM for promoting resilience analysis among stakeholders in terms of identifying key state variables that comprise an SES, evaluating alternative SES equilibrium states, and defining desirable or undesirable state outcomes through scenario analysis.
\end{abstract}

Key Words: bushmeat; fuzzy cognitive mapping; participatory modeling; resilience

\section{INTRODUCTION}

Over the last several years, considerable research effort has been dedicated to understanding the drivers of change within socialecological systems (SESs) that can alter the system's function to the point where human well-being, conservation, or other environmental management goals are compromised. These research efforts have focused primarily on analyzing and understanding the attributes governing these systems' dynamics, specifically those significant enough to shift the system into an alternative regime (Walker et al. 2004). Understanding the structure, defined dynamic relationships, and movement toward or away from alternate regimes has been suggested as a starting point to understand resilience and change across a range of SESs (see Carpenter et al. 2001, Walker et al. 2002, Brooks and Adger 2004, Folke 2006, Füssel and Klein 2006, Gallopín 2006). Although there are some variations in the literature with regard to the definition of resilience (Brand and Jax 2007) depending on the application in either an ecological (Holling 1973, Gunderson and Holling 2002) or social (Adger 2000) system context, it is generally considered to be the capacity of a system to experience shocks while retaining a certain qualitative condition, including the same identity, structure, functions, and feedbacks (Walker et al. 2004).

Following the popularity of the resilience concept, new questions have emerged regarding how the resilience paradigm can be put into practice to support environmental management. A key issue to resolve is the extent to which analytical methods that have been commonly used to characterize and communicate SES change are complementary to resilience analysis (Walters 1997, Gunderson 1999, Bennett et al. 2005). A considerable amount of research has identified the nature of SESs generally, recognizing them as dynamic, complex, adaptive, and uncertain systems with feedbacks. This has led to the development of new modeling and analytical approaches that explicitly incorporate surprises and acknowledge the potential for a system to exist in multiple states (Carpenter et al. 2002, Schwartz et al. 2011, Davidson et al. 2013) as opposed to existing in a single and dominant equilibrium state (Folke 2006).

Concurrent with this focus on incorporating complexity into resilience analysis is a call to broaden participation of the actors involved in environmental assessments (Walker et al. 2004). Because many resource decision-making contexts are characterized by low levels of controllability, high social and ecological stakes, data poverty, and heterogeneity of social agents, new modeling methods that support resilience must be informed by or constructed with stakeholder input. Additionally, these approaches should be flexible and able to be revised as new information about the system becomes available (Holling 1973, Walters 1986, Gray et al. 2014a). Such adaptive management approaches are expected to protect against self-reinforcing and inflexible decision making (so-called "rigidity traps," see Carpenter and Brock 2008). These inclusive approaches should provide opportunities to incorporate not only stakeholder beliefs to understand the perceived structure of the system (Gray et al. 2012), but also social values and preferences so that goal(s) for management and attributes that are valued about/within the system can be identified (Lynam et al. 2007).

These emerging demands for incorporating complexity and stakeholder knowledge have led to a variety of qualitative and semiquantitative techniques for perceived resilience assessment (UNECE 1998, Bennett et al. 2005, Cumming et al. 2005, Fletcher et al. 2006, Kearney et al. 2007, Kok 2009, Fuentes 2012) that have been facilitated by significant growth in the field of

\footnotetext{
${ }^{1}$ University of Massachusetts, School for the Environment, ${ }^{2}$ Coastal \& Marine Research Centre, Environmental Research Institute, University College Cork, ${ }^{3}$ VITO NV, Flemish Institute for Technological Research, ${ }^{4}$ Environmental Change Institute, University of Oxford, ${ }^{5}$ Rutgers University, Department of Human Ecology, ${ }^{6}$ University of Hawaii Manoa, Department of Natural Resources and Environmental Management
} 
participatory modeling (Sandker et al. 2010). Voinov and Bousquet (2010) outline two major objectives that drive participatory modeling: (1) to increase and share knowledge and understanding of a system and its dynamics under various conditions and (2) to identify and clarify the impacts of solutions to a given problem. Although there has been a recent increase in participatory tools and software available to environmental managers, some critics have cautioned that the diversity of modeling practices does not necessarily indicate diversity in function because new stakeholder-driven modeling programs are often prone to duplication of efforts (Jones et al. 2008).

Even though norms for understanding the characteristics of SESs have been established and the development of participatory modeling approaches has increased during the last decade, the trade-offs between modeling tools in terms of ease of use with stakeholders, model inputs, and outputs are only recently becoming understood. Scholars in the field have lately begun to review the strengths and weaknesses of different participatory approaches (Lynam et al. 2007, Sandker et al. 2010, Voinov and Bousquet 2010); however, this work is rarely explicitly linked to the concepts used in resilience assessments, despite some notable recent efforts (see Ross and Berkes 2014).

To contribute to this discussion, we compare how one specific participatory modeling approach, fuzzy cognitive mapping (FCM), can be explicitly used to support the resilience framework, specifically with regard to incorporating the valuable knowledge held by stakeholders. We use a case study for bushmeat hunting in Tanzania to demonstrate the value of FCM in collecting and standardizing the perceptions of stakeholders to identify and analyze key state variables. Further, by using the capacity of FCM to support semiquantitative scenario analyses, we illustrate the relationship between the current and projected equilibrium states of the bushmeat trade system and their relationships to desired/ undesired state outcomes under current pressures and various potential management actions.

\section{FUZZY COGNITIVE MAPPING}

Originally developed by Kosko (1986) as a semiquantitative and dynamic method to structure expert knowledge, FCM has historical roots in cognitive mapping (Axelrod 1976). Similar to other cognitive maps, FCMs are graphical representations of a system that visually illustrate the relationships or edges between key concepts, or nodes, of the system, including feedback relationships. The relationships in a structural map are logically defined by connecting concepts through semantic or otherwise meaningful directed linkages (Novak and Cañas 2008). The justification for representing cognition by means of structural maps is derived from constructivist psychology (Gray et al. $2014 b$ ), which suggests that individuals interactively construct knowledge by creating internal associative representations that help catalogue, interpret, and assign meaning to environmental stimuli and experiences (Raskin 2002). Knowledge constructed in this manner can externally represent the foundation of an individual's organized understanding of the workings of the world around him or her. Therefore, cognitive maps can be considered external representations of internal mental models (Jones et al. 2011). Individuals assimilate external events and accommodate information into these mental model structures to facilitate reasoning and exchange understanding (Craik 1943,
Flavell 1996, Lerner 1998). Using this theoretical framework, cognitive maps can be elicited to represent an organized understanding of a general context or domain, thereby providing an illustrative example of a person's internal conceptual structure of the issue in question (Novak and Cañas 2008).

FCMs build on these notions and are highly structured and parameterized versions of cognitive maps that represent direct and indirect causality by combining aspects of fuzzy logic, neural networks, semantic networks, and nonlinear dynamic systems (Glykas 2010) in influential diagrams. Because FCMs are based on cognitive mapping and are semiquantitative, they can be considered representations of mathematical pairwise associations using qualitatively, e.g., low, medium, or high, or quantitatively assigned weighted edges between -1 and 1 among variables that collectively constitute a representation of a particular domain (Wei et al. 2008). These pairwise relationships allow computation of the cumulative strength of connections between the elements with weighted edges, highlighting any domain as a system (see Fig. 1). Typical strengths of FCMs are the simple algorithms used, transparent representation of system feedback structure, and the possibility to mathematically average or weight different FCMs from several individuals, e.g., scientific and local experts, or domains, e.g., natural and social sciences, into one model.

FCMs have been used in a number of disciplines to indicate relationships among variables as well as to understand and communicate system dynamics. The applications of FCM can be categorized in terms of the type of knowledge being represented in the cognitive map and the perceptions they reflect (Gray et al. $2014 b$ ). Broad disciplinary categories include traditional scientific experts (Hobbs et al. 2002), engineers (Amer et al. 2011), physicians (Benbenishty 1992), and local experts including pastoralists (Ortolani et al. 2010, Papageorgiou and Kontogianni 2012, Halbrendt et al. 2014), fishermen (Mackinson 2000, Wise et al. 2012), environmental managers (Gray et al. 2013, 2014c), and groups of several environmental stakeholders as a way to facilitate shared decision making (Özesmi and Özesmi 2004, Kafetzis et al. 2010, Gray et al. 2012, Meliadou et al. 2012, Papageorgiou and Kontogianni 2012, Jetter and Kok 2014).

Fig. 1. An example of a simple fuzzy cognitive map (FCM), illustrating weighted edge relationships $(-1,1)$ between system elements A, B, C, and D.

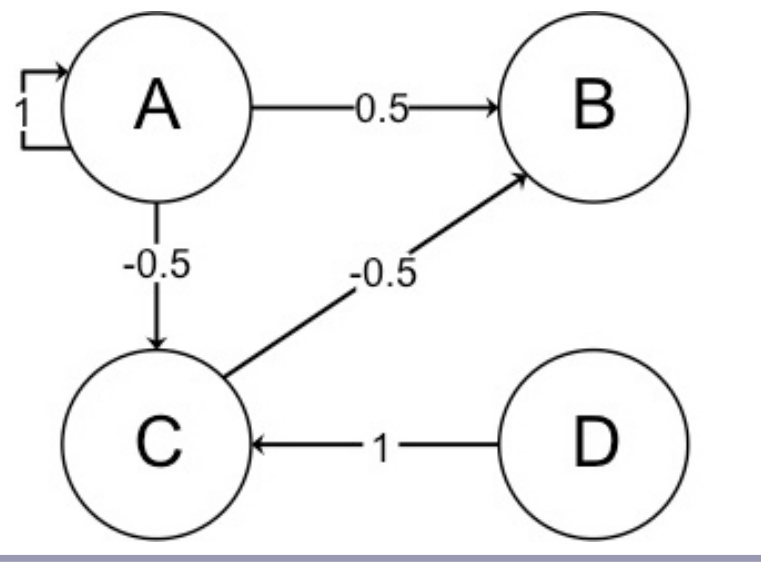


We focus on the use of FCM as a means of encoding and aggregating stakeholder and/or expert knowledge into a standardized format, thus allowing a broad range of knowledge types to be integrated and communicated in pursuit of SES resilience assessments. These external representations provide a tangible way to allow knowledge claims regarding the structural and functional identity of the system subjected to management to be debated (Özesmi and Özesmi 2004, Amici et al. 2010, Wildenberg et al. 2010). Further, the application of FCM in a participatory modeling context provides an adaptable method to support existing resilience assessment frameworks previously outlined in the literature (e.g., Walker et al. 2002). We suggest that FCM can be used to understand change and transition in SESs by (1) sharing knowledge to define the state space of a given SES, (2) analyzing the structure of an SES, (3) analyzing SES functions through scenarios, and (4) evaluating how changes to structural configurations may relate to movement toward or away from desirable or undesirable future trajectories (Fig. 2).

Fig. 2. Mapping the participatory fuzzy cognitive mapping (FCM) approach to social-ecological system (SES) resilience assessment that we propose to the framework put forward by Walker et al. (2002).

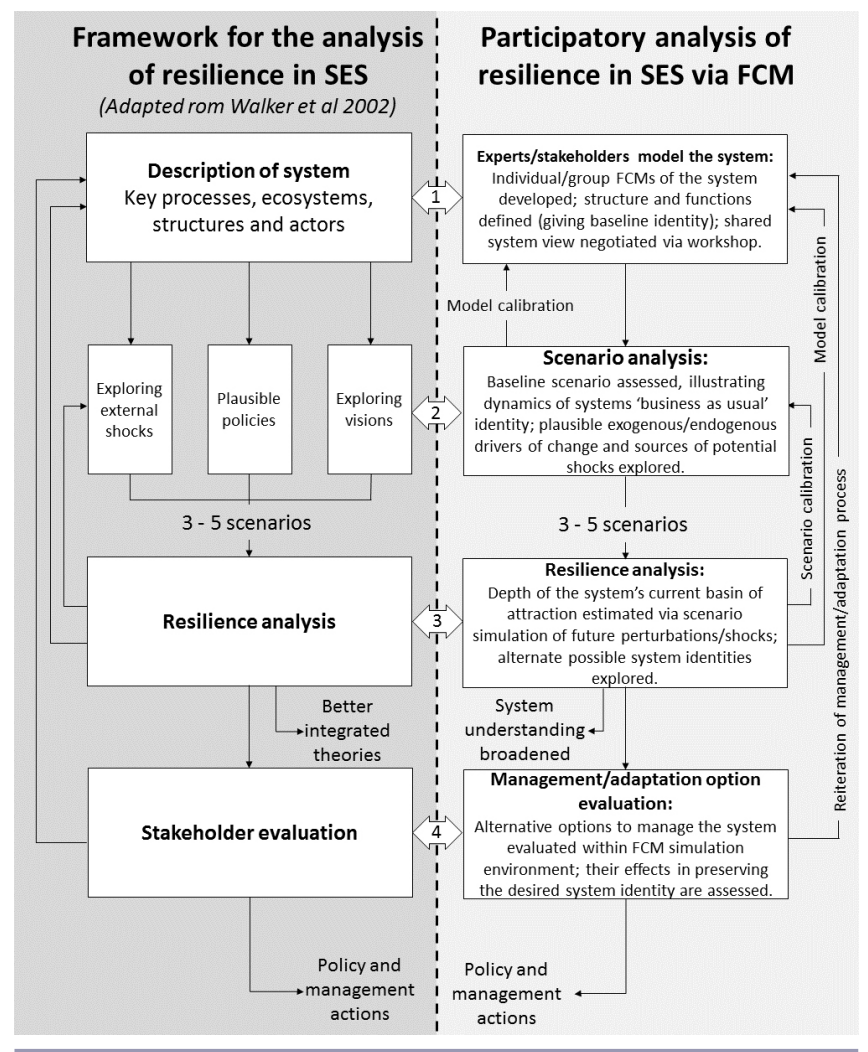

Constructing FCM based on shared community knowledge to define the state space

FCMs also have been proposed as a unique tool for aggregating diverse sources of knowledge to represent a scaled-up version of individuals' knowledge and beliefs (Özesmi and Özesmi 2004). The product of the aggregation of individual FCMs is sometimes referred to as a social cognitive map and is considered to be a representation of shared knowledge (Özesmi and Özesmi 2004, Gray et al. 2012, 2014c). The concept of shared knowledge in the form of social cognitive maps has been used for a variety of purposes: to gain a more comprehensive understanding of complex systems, to describe consensus in knowledge among individuals, and to define differences in individual and group belief or knowledge structures. By applying FCM to understand change within an SES, we focused on engaging in communitygenerated modeling activities via workshops with a range of stakeholders to generate a working model of the salient social and ecological components that constitute a resource system in relation to environmental change. Such definitions of the variables that are contained within the perceived boundaries of a system lend themselves to the idea of defining the state space in resilience analysis (Walker et al. 2004). This is the multidimensional state within which all combinations of the defined variables can exist. These definitions of what constitutes the state space of an SES are the components/variables that exist within a given space, e.g., a protected area, or are required for a system to have a given function, e.g., international timber trade. Additionally, the relationships between state space variables that are defined in terms of degrees, e.g., low, medium, or high, of positive or negative influence together represent the networked structure of a system.

\section{Analyzing FCM structure}

Because FCMs are derived from graph theory and are semiquantitative, the static structure between state space variables can be represented in mathematical terms (Table 1). These structural measures are determined by translating the cognitive map into an adjacency matrix and translating the positive or negative values that define relationships between variables on a scale between +1 and -1 (Table 1). Representing the structural relationships of these concepts in a matrix allows each variable included in a model to be categorized in one of three ways: as a driving variable, i.e., forcing component; receiving variable, i.e., impacted component; or ordinary variable, i.e., intermediate component (Nyaki et al. 2014). A variable's relative importance for the system can be determined by the strength of its incoming and outgoing edge relationships relative to those of other variables via centrality measurements common to network analyses (see Özesmi and Özesmi 2004). FCMs can also be characterized by a range of other quantitative metrics allowing comparison of one model with another by measuring the general structure of the model, including dimensions like complexity and density (see Gray et al. $2014 b$ for a review of structural metrics).

Table 1. Adjacency matrix derived from the fuzzy cognitive map of Figure 1.

\begin{tabular}{llccl}
\hline \hline & $\mathrm{A}$ & $\mathrm{B}$ & $\mathrm{C}$ & $\mathrm{D}$ \\
\hline $\mathrm{A}$ & 1 & 0.5 & -0.5 & 0 \\
$\mathrm{~B}$ & 0 & 0 & 0 & 0 \\
$\mathrm{C}$ & 0 & -0.5 & 0 & 0 \\
$\mathrm{D}$ & 0 & 0 & 1 & 0 \\
\hline
\end{tabular}

\section{Analyzing FCM dynamics: current basin of attraction}

In addition to defining the state space and the structured relationship between variables, the results of dynamic interactions 
between structured components within a domain can be determined using matrix calculations through FCM scenarios. The output of an FCM's adjacency matrix is calculated using matrix algebra over a series of iterations to illustrate its baseline scenario, i.e., a representation of the steady state of the system (Kosko 1986, 1994). The steady state of a system is complementary to the resilience concept of a basin of attraction (Walker et al. 2004). This provides a snapshot of how the variables and linkages of the system given the current SES configuration would resolve themselves in the absence of change or intervention, with all feedback loops played out:

$$
A_{i}^{(k+1)}=f\left(A_{i}^{(k)}+\sum_{\substack{j \neq i \\ j \neq i}}^{N} A_{j}^{(k)} w_{j i}\right)
$$

where $\mathbf{A}_{i}^{(k+1)}$ is the value of factor $V_{i}$ at iteration step $k+1, \mathbf{A}_{i}^{(k)}$ is the value of factor $V_{i}$ at iteration step $k, \mathrm{~A}_{j}^{(k)}$ is the value of factor $V_{j}$ at iteration step $k$, and $w_{j i}$ is the weight of the edge relationship between $V_{i}$ and $V_{j}$. Threshold function $f$ (e.g., logistic or sigmoidal function) is used to normalize the values at each step to keep the dynamic analysis bounded. This initial state of the system, calculated based on the network structure and defined influences between variables, indicate the region in state space in which the system tends to remain (Walker et al. 2004) without significant changes to any state space variable.

\section{Analyzing FCM dynamics: alternative stable states}

Inferences may be drawn regarding the dynamic attributes of the system as modeled by analyzing the scenario output of an FCM (Özesmi and Özesmi 2004). Analysis of the scenarios can either focus on the equilibrium end states, if present, or the transient behavior during the iteration steps. "What if" scenarios help explore how the system might shift into another set of equilibrium points within the same basin of attraction, or slip into an alternative regime under a range of possible conditions as variables included in the state space are artificially changed. This is accomplished by increasing or decreasing (referred to as "clamping") key variables as continually high or low (Kosko 1986, 1994), resulting in a new system state that can be compared with the steady state.

The persistence of a system's identity in the face of disturbance has been suggested as a useful measure of resilience (Cumming et al. 2005). Therefore, by comparing current basins and alternative equilibrium states, it is possible to characterize a system's current identity and determine the scale of disturbance it can endure while maintaining a certain output (Kok 2009). Such assessments draw on the concept of "stability landscapes" described by Walker et al. (2004) to describe the transition between alternative equilibrium states within a basin.

\section{Reviewing equilibrium points and defining desirable and undesirable states under different scenarios}

In addition to understanding the structure and function of SESs, the modeling process itself, i.e., developing an FCM with stakeholders, has also helped policy makers frame regulations in a manner responsive to the needs and terms of stakeholders and maximize stakeholder buy-in of experimental policy measures
(Özesmi and Özesmi 2004). Murungweni et al. (2011) further emphasize the potential of the FCM modeling process to form strong links of communication and trust between stakeholders, researchers, and policy makers.

To date, however, less attention has been paid in the literature to defining desired and undesired states of an SES using FCM based on the perceived system components included in a model. To add to the discussion, we suggest that all concepts included in an FCM that are thought to be important to the composition of state space (Walker et al. 2004) can be designated as existing in one of three states. Thus, stakeholders can indicate a preference that a concept is increasing, preference that a concept is decreasing, or showing no preference. Defining preferred states establishes system desirability in the face of external or internal pressures. Further, this explicit approach establishes a qualitative basis for understanding the system's identity, to which its current basin of attraction or alternative equilibrium state under a scenario can be compared (Walker et al. 2004).

\section{CASE STUDY}

To highlight the conceptual and analytical linkages between FCM and resilience analysis, we present case study data modeling changes to wildlife populations and community well-being in relation to increasing immigration to the area. The data were collected from a local-expert workshop in a village that borders the Serengeti National Park in Tanzani.

Wildebeest and zebra populations and bushmeat consumption in villages near the Serengeti National Park

An increase in bushmeat hunting in protected areas poses great risks to many threatened and endangered species. The cumulative impacts of extreme poverty, advances in hunting techniques, and increased human populations near protected areas have heightened the demand for bushmeat and significantly endangered wildlife populations (Knapp 2012, Rentsch 2012, Nyaki et al. 2014). Although the term "bushmeat" refers to the hunting and consumption of all wildlife, on-going and extensive bushmeat hunting has been particularly damaging to the endemic biota of Africa, causing some species to be classified as threatened or endangered (Ndibalema and Songorwa 2008, Mfunda and Røskaft 2010) and resulting in hunting restrictions and even moratoriums for many species.

The high profit returns from selling bushmeat on the black market and low capital investment of bushmeat hunting have attracted significant inbound migration of human populations to areas close to the borders of protected areas. For example, the human population living along the western edge of Serengeti National Park is increasing at an average rate of $2.9 \%$ per year (Ndibalema and Songorwa 2008, Knapp 2012, Rentsch 2012). Of the approximately one million people estimated to live along the borders of the protected areas of the Serengeti National Park, between 52,000 and 60,000 people are estimated to engage in illegal hunting (Loiboki et al. 2002, Knapp 2012), a number that is predicted to increase in line with population growth. In addition, increasing human populations alongside protected areas not only impact wildlife directly through predation of bushmeat species, but also indirectly by way of resource competition, diminution of wildlife habitat, encroachment, and increases in human-wildlife conflicts such as crop destruction from wildlife and disease transmission (Estes et al. 2012). 
To define the perceived state space of the community in relation to hunting in the protected area, the current basin of attraction, and anticipated changes to system states based on the perceptions of local stakeholders within the system, we present data collected from a participatory modeling workshop with 15 zebra and wildebeest hunters, bushmeat consumers, and bushmeat sellers in one village near the Serengeti National Park in Tanzania. Individuals who participated in the workshop were nominated by a larger group from the local community based on their individual expertise (see Nyaki et al. 2014). Through extensive discourse and collaboration, participants defined the structure of the system and defined its preferred state identity. After data were collected, the model was analyzed for shifts toward or away from this identity under stakeholder-defined scenarios to understand its current and future trajectories.

\section{Step 1: Modeling bushmeat consumption and production in} Tanzania using FCM

A workshop was held in coordination with an international nongovernmental organization working to develop policies to reduce bushmeat hunting in communities near protected areas. This workshop was facilitated by an academic researcher who also had connections to local community members. During the workshop, an unrelated FCM of an agricultural system was used to lead discussions about how to generate a model.

Two central concepts were provided to guide FCM construction: bushmeat consumption and zebra/wildebeest populations. Workshop participants then participated in a brainstorming session to identify other components that were important to be included in the model. They began to structurally link these components using directed arrows and qualifying the degree of influence among these connections using these descriptors: high, medium, and low positive and high, medium, and low negative. The final model defined a state space consisting of 22 components with 52 connections between the components (Fig. $3)$. The components perceived as most important to the system, i.e., those with the highest centrality scores, were (1) poaching, (2) increased human population, (3) poor crop harvest, (4) crop destruction, and (5) bushmeat market demand.

After the model was developed, workshop participants discussed the preferred state of the system through deliberation until agreement was reached. This was accomplished by identifying their opinions about each component of the model in terms of whether they held a preference that a concept would increase (e.g., income, crop availability), preference that a concept would decrease (e.g., disease), or indicated no preference either way (e.g., hunting regulations). This evolved into a representation of the preferred state identity that was considered as desirable.

Step 2: Scenario analysis: current basin of attraction After the workshop participants were satisfied with their model, a photograph of the model was taken so it could be translated into an adjacency matrix for scenario analyses (Özesmi and Özesmi 2004). Further, the model was entered into the FCMbased software Mental Modeler (see http://www.mentalmodeler. org, Gray et al. 2013) for scenario analyses (Fig. 4). Subsequently, the steady state was calculated, indicating the current basin of attraction given the parameters defined between components by the workshop participants (Fig. 5).
Fig. 3. Photograph of fuzzy cognitive mapping (FCM) constructed in the workshop by the community that indicates conceptual links between zebra and bushmeat populations and bushmeat consumption.

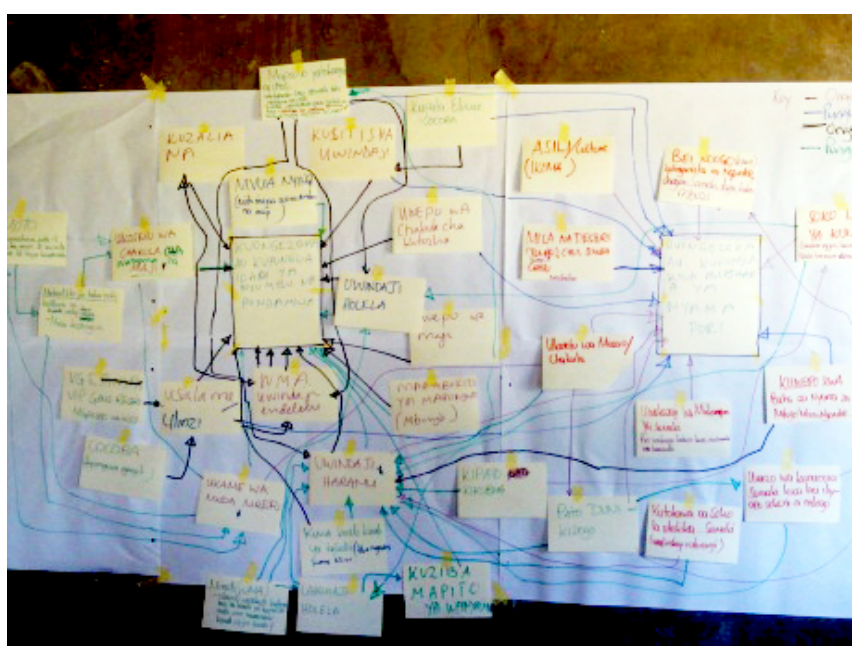

Step 3: Resilience analysis: identifying drivers of socialecological change

During the workshop, participants identified increased human population as being the most concerning change to environmental conditions affecting their village. The community model was then subjected to a scenario in which the concept of increased human population was "clamped" as high (see Kosko 1986 for a description of FCM scenario analysis). The outcome of this scenario was compared with the baseline steady-state scenario to understand relative change of state space variables under this condition (see the Increased Human Population scenario, Fig. 6). This scenario provided a useful illustration of how the system might settle into an alternative equilibrium state, in terms of the relative change of components included in the FCM, as human population increases. This output was compared with the preferred state conditions of each component to determine the level of desirability of the SES state that results as human population increases.

\section{Step 4: Management/adaptation option evaluation}

To understand how management plans might mitigate unwanted outcomes and influence the level of desirability of a system under the scenario of increased human populations, two new variables were added to the state space. The added variables were establishing (1) community wildlife management (CWM) and (2) hiring community engagement officers to serve as liaisons between the CWM and the local community. The two new variables represented possible policy actions that might mitigate some unwanted impacts associated with the increasing human population; they were added to the community model by defining their structural relationships and relative influences on other components (Figs. 7 and 8).

Once these new components were added to the community model, the increasing human population scenario was run again along with the added strategies meant to mitigate its unwanted impacts 
Fig. 4. Screenshot of community model entered into fuzzy cognitive mapping (FCM) software Mental Modeler. Blue lines indicate positive relationships and orange lines represent negative relationships between components. Line thickness indicates the degree of influence between components. CWA indicates community wildlife management area; SRCP, a local microcredit lending program.

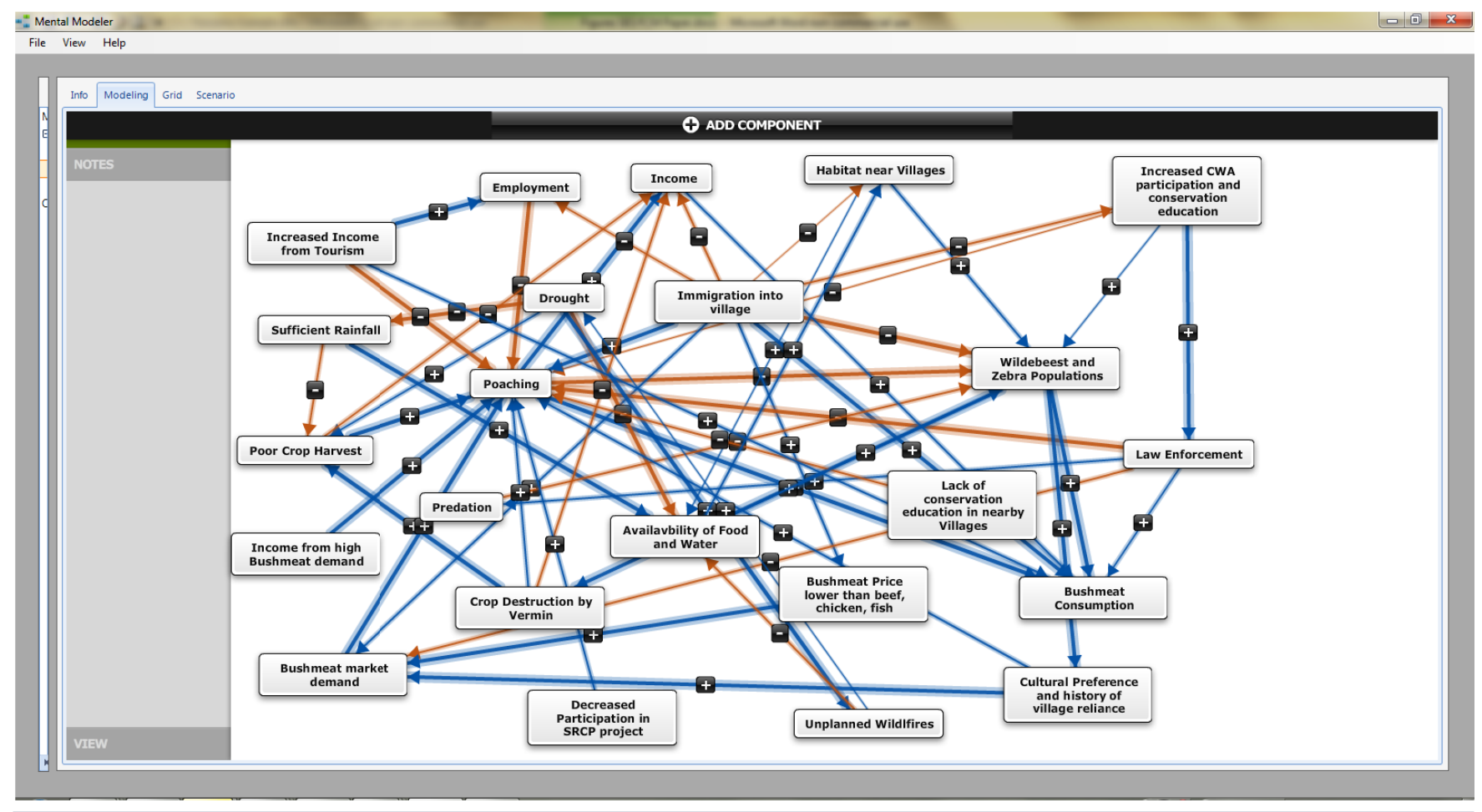

(see Increased Human Population plus Mitigation, Fig. 6) to understand how these new strategies or configurations might influence alternative equilibrium states. All scenarios were then compared to understand (1) system states under pressures and (2) the stability landscape under pressure and mitigation plans (Fig. 6). After the workshop, these scenario outputs were compared by researchers to understand how scenario states compared to stakeholder-defined preferred states identified during workshops.

\section{Results}

Of the 22 components included in the model, workshop participants showed preference for 15 components as increasing or decreasing (Table 2). Steady-state analysis indicated that in comparison to the desired state, the current basin of attraction led to a state in which $33 \%$ of the state variables would exist in a favorable state, in general terms of positive or negative, including income, availability of food and water for animals, suitable wildlife habitat near villages, employment, and a small positive increase in zebra and wildebeest populations. The steady-state analysis also indicated that $40 \%$ of the variables included in the model existed in a state that was counter to the preferred state; one of these was poaching, which showed a substantial increase under status quo conditions. Additionally, poor crop harvests increased, which participants preferred to see decrease, while sufficient rainfall decreased, which participants preferred to see increase. There was no change, either positively or negatively, for the remaining four variables for which participants indicated preference.
Scenario results indicated that when human population increased, $74 \%$ of the 15 variables that constituted the preferred state showed a trajectory away from a desired state $(33 \%)$ or no change $(41 \%)$, whereas $26 \%$ indicated a trajectory toward a preferred state. Under this scenario, the state variables that maintained a preferred state were a decrease in crop destruction by vermin, a decrease in poor crop harvests, and an increase in availability of food and water and habitat near villages. When management plans were added to the scenario of increased human populations for comparison, $67 \%$ of the components indicated a shift toward a preferred state, although the influence of the proposed management action was not distributed evenly. Specifically, only income and participation (13\%) shifted from negative values to positive values, an indication that these components were perceived to be most affected by the management action and to foster a more preferred state of the system by crossing a threshold from an undesired state to a desired state.

\section{DISCUSSION}

Although the focus of this research was to align FCM explicitly with participatory forms of resilience analysis, it is important to note that a growing number of participatory planning and modeling approaches are available to understand socialecological dynamics (Lynam et al. 2007). Examples include narrative scenario planning (Swart et al. 2004), concept mapping (Harr et al. 2014), Bayesian belief networks (Aalders 2008), and agent-based modeling (Janssen and Ostrom 2006), among others. Although many of these tools have the potential to support different dimensions of resilience analysis, there are trade-offs to 
Fig. 5. Scenario analysis of steady state that indicates the current basin of attraction for state space variables under status quo conditions independent of environmental or social change. BM indicates bushmeat; CWA, community wildlife management area; FCM, fuzzy cognitive mapping; SRCP, a local microcredit lending program.

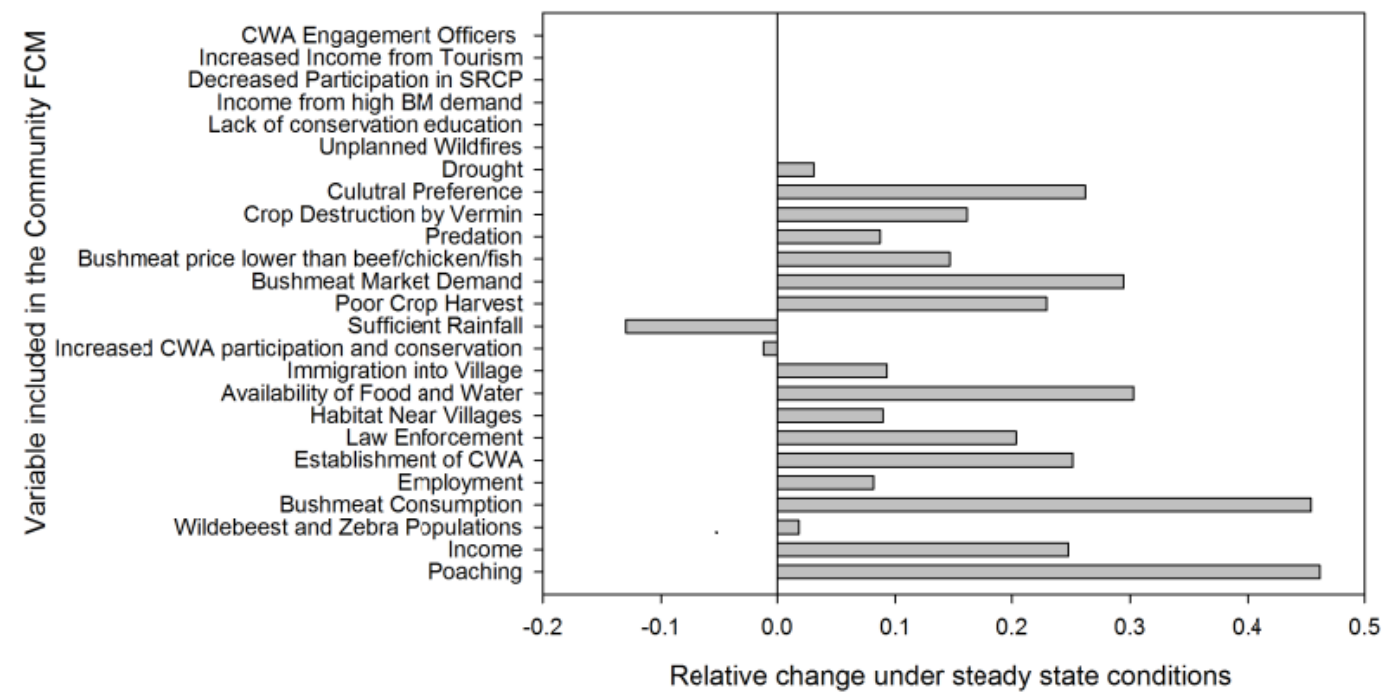

Current Basin of Attraction based on paramterized values

Fig. 6. Comparison of desirability of system states under two scenarios: (1) increased human population (given model shown in Fig. 4) and (2) increased human population with the following mitigation plans: establishment of community wildlife management area (CWA) and establishment of CWA community engagement officers (models shown in Figs. 7 and 8 ). Results indicate that changing the configuration of the system to include the mitigation strategies moves 10 of the 25 variables in a desirable state direction while having no effect on other variables. FCM indicates fuzzy cognitive mapping; SRCP, a local microcredit lending program.

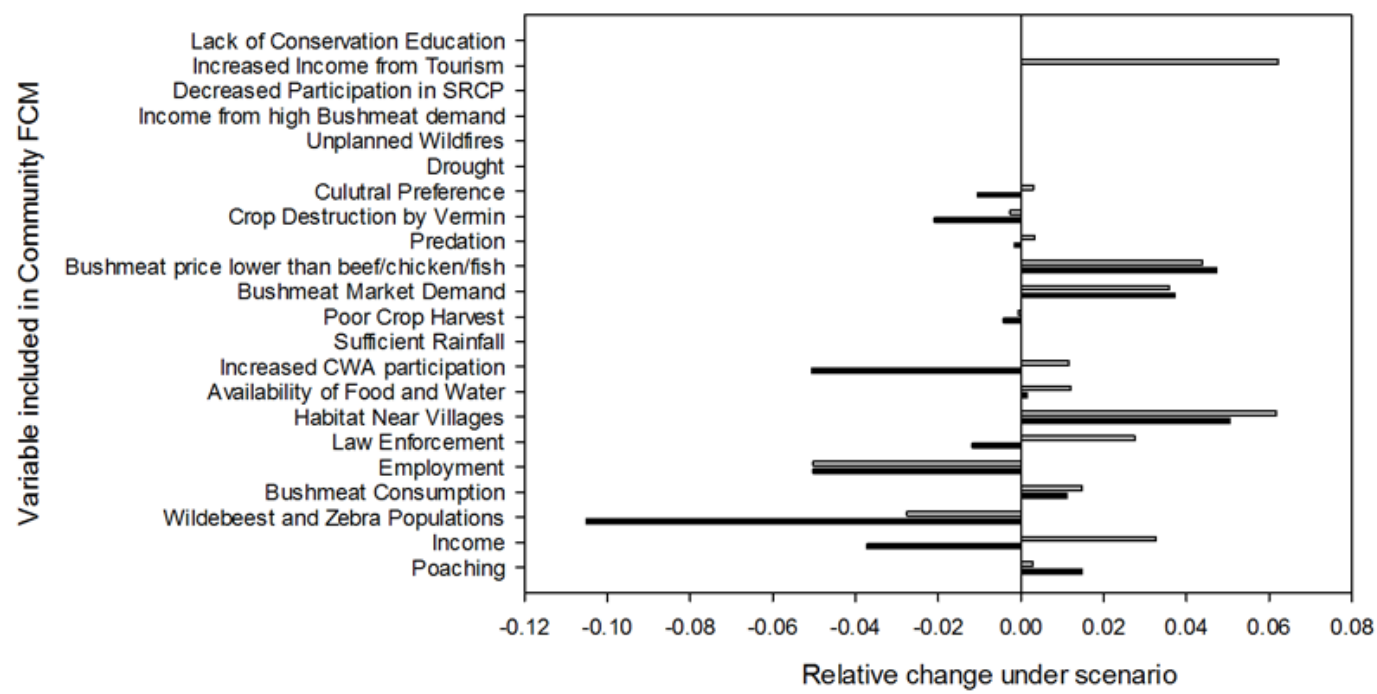

Increased Human Population Increased Human Population with Mitigation Plans 
Fig. 7. Screenshot of mitigation plan, adding to the model the concept of establishment of community wildlife management area (CWA) and its perceived structural relationships to other components.

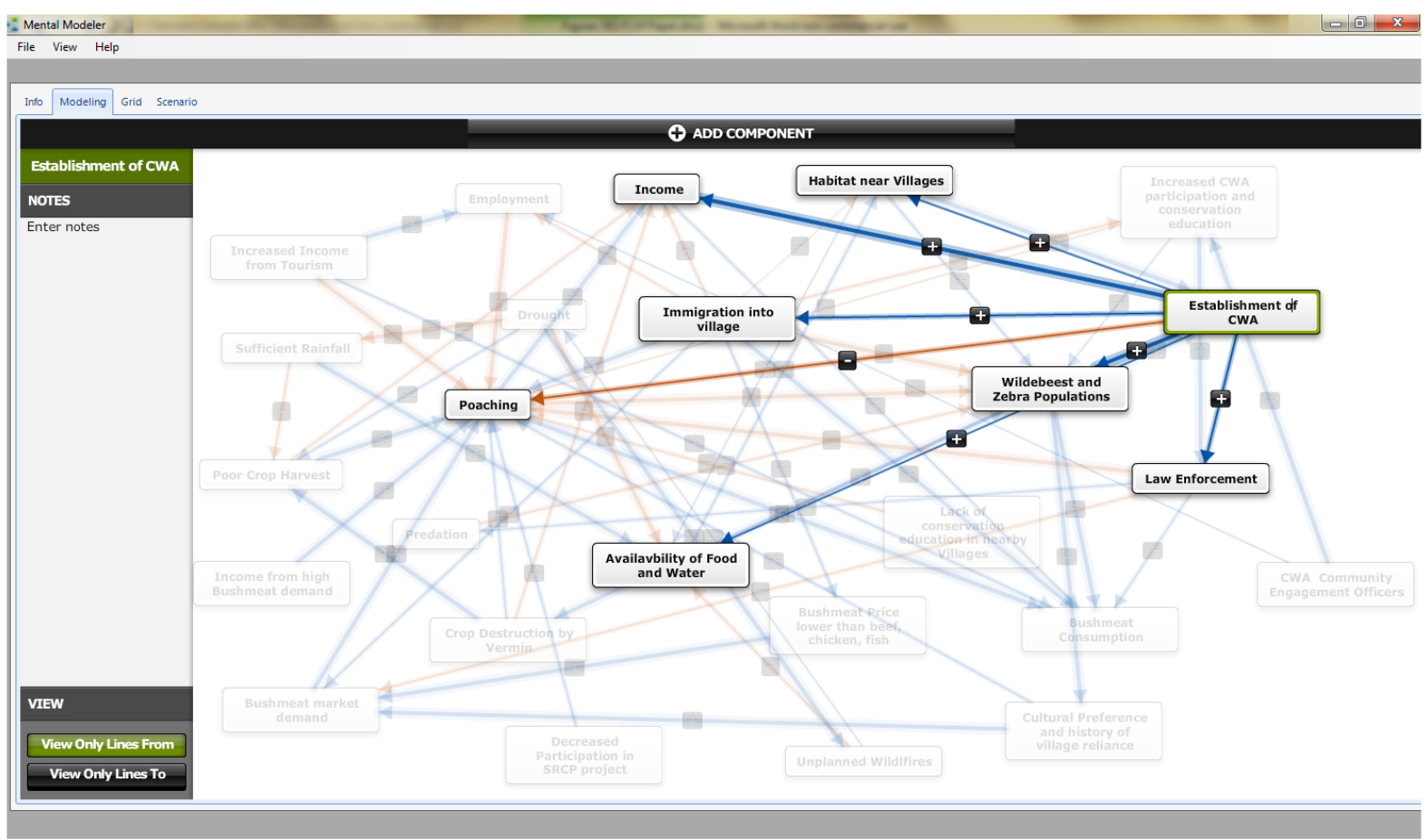

Fig. 8. Screenshot of mitigation plan, adding to the model the concept of community wildlife management area (CWA) community engagement officers and the perceived structural relationships to other components.

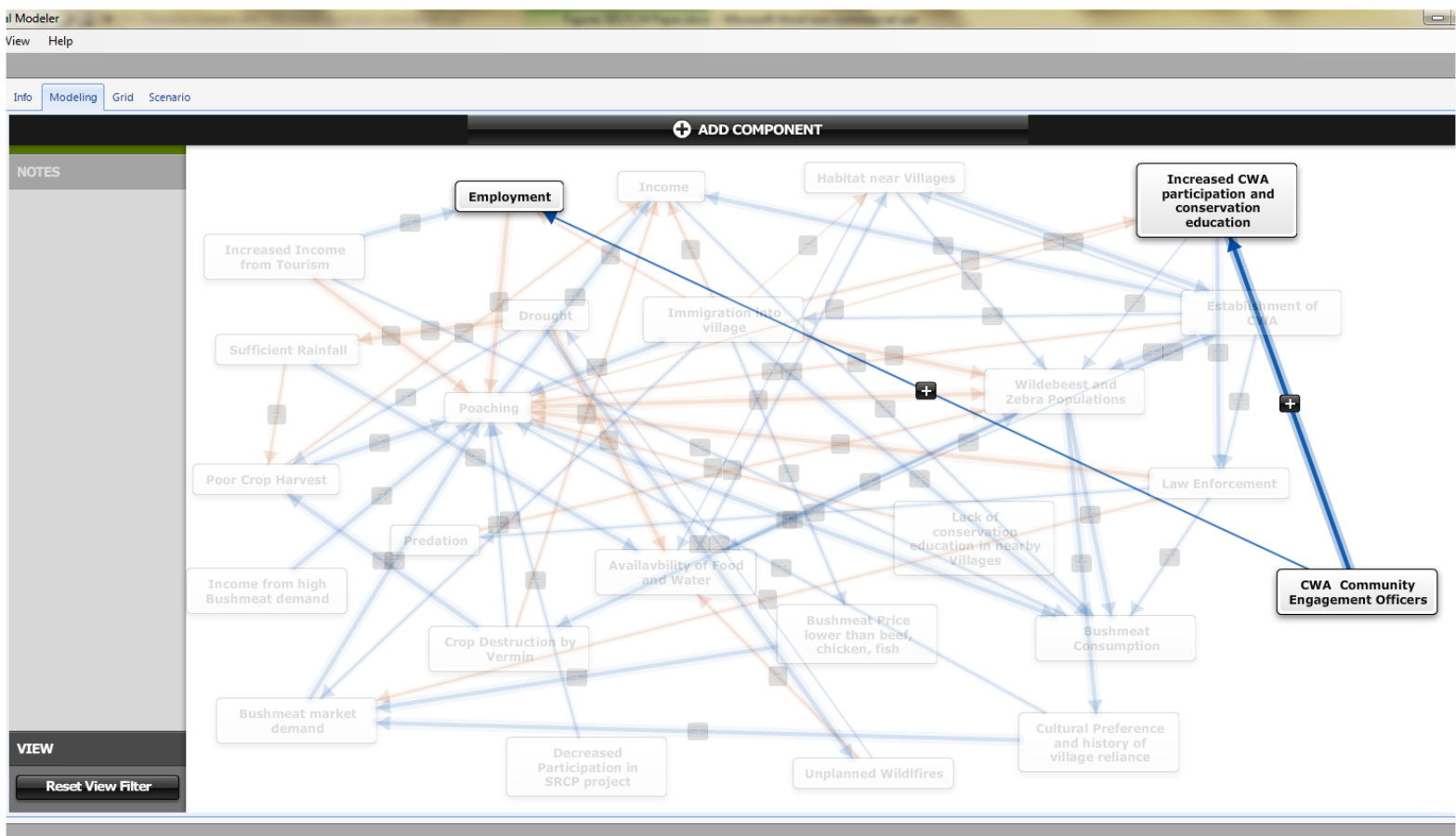


Table 2. Comparison of scenario analyses and preferred state of the social-ecological system.

\begin{tabular}{|c|c|c|c|c|}
\hline $\begin{array}{l}\text { Component included in the community } \\
\text { model }\end{array}$ & Desired Change & $\begin{array}{l}\text { Scenario: Increased } \\
\text { population }\end{array}$ & $\begin{array}{c}\text { Scenario: } \\
\begin{array}{c}\text { Increased population plus } \\
\text { mitigation }\end{array} \\
\end{array}$ & $\begin{array}{l}\text { Desired Change Achieved } \\
\quad(\text { Yes }=1, \text { No }=0)\end{array}$ \\
\hline Lack of conservation education & Decrease & 0 & -0.06175 & 1 \\
\hline $\begin{array}{l}\text { Decreased participation in a local } \\
\text { microcredit lending program }\end{array}$ & Decrease & 0 & 0 & 0 \\
\hline Unplanned wildfires & Decrease & 0 & 0 & 0 \\
\hline Drought & Decrease & 0 & 0 & 0 \\
\hline Crop destruction by vermin & Decrease & -0.02087 & -0.00259 & 1 \\
\hline Poor crop harvest & Decrease & -0.00413 & -0.00066 & 1 \\
\hline Poaching & Decrease & 0.01487 & -0.00066 & 1 \\
\hline Income from tourism & Increase & 0 & 0.06218 & 1 \\
\hline Sufficient rainfall & Increase & 0 & 0 & 0 \\
\hline $\begin{array}{l}\text { Increased community wildlife management } \\
\text { participation }\end{array}$ & Increase & -0.05059 & 0.01158 & 1 \\
\hline Availability of food and water & Increase & 0.00159 & 0.01195 & 1 \\
\hline Habitat near villages & Increase & 0.05055 & 0.06175 & 1 \\
\hline Employment & Increase & -0.05022 & -0.05022 & 0 \\
\hline Wildebeest and zebra populations & Increase & -0.10509 & -0.02756 & 1 \\
\hline Income & Increase & -0.03719 & 0.03264 & 1 \\
\hline $\begin{array}{l}\text { Bushmeat price lower than beef/chicken/ } \\
\text { fish }\end{array}$ & Neutral & 0.04727 & 0.04389 & - \\
\hline Cultural preference & Neutral & -0.01055 & 0.00303 & - \\
\hline Predation & Neutral & -0.00140 & 0.00335 & - \\
\hline Bushmeat market demand & Neutral & 0.03724 & 0.03585 & - \\
\hline Law enforcement & Neutral & -0.01170 & 0.02750 & - \\
\hline Bushmeat consumption & Neutral & 0.01112 & 0.01487 & - \\
\hline Income from bushmeat demand & Neutral & 0 & 0 & - \\
\hline
\end{tabular}

consider. As these approaches become more mainstream, it is important to select participatory modeling methods based on the community involved in the modeling process, research questions or management goals, and how each tool differs across dimensions such as ease of use with stakeholders, model inputs and outputs, and the degree of spatial or temporal extent. Although the theory behind each of these methods continues to develop along with new methodological and technological advances, we provide a general overview of the some of the strengths and weakness of different approaches (Table 3).

For example, certain methods may be more or less amenable to different groups involved in the modeling process based on the amount of training required to create and analyze a model. Although narrative scenario analysis and qualitative concept mapping lend themselves to use across a wider range of communities because they are more flexible than semiquantitative approaches, the output of these models is often not dynamic, limiting their ability to be used to evaluate competing system states through post hoc analyses. Additionally, although most methods to varying degrees allow stakeholders and scientists to define the concepts, components, or variables that constitute the state space of the system modeled, some methods are more flexible in terms of the types of relationships that can be defined between variables. FCM and agent-based modeling, for example, can represent feedback relationships between variables, whereas Bayesian belief network relationships are unidirectional. Further, although all SESs modeled through these efforts are defined in terms of time and space to some extent, the degree to which model outputs can be interpreted in spatial or temporal units by stakeholders varies and thus may influence analytical abilities to draw meaningful conclusions that facilitate management action. When considered together on a spectrum, as tools transition from more flexible and qualitative to more parameterized and semiquantitative, ease of stakeholder use decreases along with the ability to explicitly evaluate competing system states. Further, although semiquantitative approaches may provide a wide range of opportunities for post hoc analysis, they may limit the degree to which stakeholder values and knowledge are integrated into model-based assessments.

It is also important to highlight that although there has been a dramatic increase in the use of FCM across multiple scientific fields (Papageorgiou and Salmeron 2013), even proponents of the method have begun to identify some analytical weaknesses in the approach. In fact, several of the methodological shortcomings that have recently been identified may present significant issues when attempting to model and analyze the complexity found in many SESs. For example, in their review Papageorgiou and Salmeron (2013) indicate that FCMs are limited in their ability to model time delays with regard to the interactions between nodes and are limited to defining linear relationships within a system. Additionally, they point out that FCM dynamics are of the first order; that is, the next system state depends on the previous one, and therefore the approach does not deal well with the randomness associated with many complex domains. Because SESs often, if not always, include nonlinear relationships, thresholds at which system states can change significantly are prone to surprises that are at times dramatic and, by definition, unexpected (Carpenter et al. 2002, Schwartz et al. 2011, Davidson et al. 2013) it is clear that FCMs are a useful "quick and dirty" 
Table 3. Comparison of participatory modeling as they relate to participatory resilience modeling.

\begin{tabular}{|c|c|c|c|c|c|c|}
\hline $\begin{array}{l}\text { Modeling } \\
\text { Approach/ } \\
\text { Tool }\end{array}$ & $\begin{array}{l}\text { Ease of use } \\
\text { with } \\
\text { stakeholders }\end{array}$ & $\begin{array}{l}\text { Model input collected } \\
\text { from stakeholder }\end{array}$ & $\begin{array}{l}\text { Model outputs } \\
\text { presented to } \\
\text { stakeholders }\end{array}$ & $\begin{array}{l}\text { Spatial or } \\
\text { Temporal }\end{array}$ & $\begin{array}{l}\text { Strengths in participatory } \\
\text { social-ecological system } \\
\text { (SES) resilience analysis? }\end{array}$ & $\begin{array}{l}\text { Weaknesses in participatory } \\
\text { SES resilience analysis? }\end{array}$ \\
\hline $\begin{array}{l}\text { Narrative } \\
\text { scenario } \\
\text { analysis }\end{array}$ & High & $\begin{array}{l}\text { Focus group discussions; } \\
\text { envisioning future states } \\
\text { under parameterized } \\
\text { conditions; system } \\
\text { components defined }\end{array}$ & $\begin{array}{l}\text { Alternative } \\
\text { system states, } \\
\text { usually } \\
\text { qualitatively } \\
\text { defined }\end{array}$ & Temporal & $\begin{array}{l}\text { Stakeholder driven, less } \\
\text { constrained and highly } \\
\text { flexible given stakeholder } \\
\text { priorities }\end{array}$ & $\begin{array}{l}\text { Scenario outputs are often } \\
\text { constrained to the contexts } \\
\text { where data are collected. } \\
\text { Qualitative output often } \\
\text { must be translated into } \\
\text { quantitative or } \\
\text { semiquantitative format for } \\
\text { additionally model coupling }\end{array}$ \\
\hline $\begin{array}{l}\text { Qualitative } \\
\text { Concept- } \\
\text { mapping }\end{array}$ & High & $\begin{array}{l}\text { Concepts/system } \\
\text { components and } \\
\text { associations/ } \\
\text { relationships between } \\
\text { components defined }\end{array}$ & $\begin{array}{l}\text { System structure, } \\
\text { static qualities } \\
\text { and } \\
\text { characteristics of } \\
\text { the system }\end{array}$ & Neither & $\begin{array}{l}\text { Provides representation of } \\
\text { a problem space and the } \\
\text { associations and } \\
\text { characteristics of the } \\
\text { problem space }\end{array}$ & $\begin{array}{l}\text { Static and therefore not } \\
\text { suitable for scenario } \\
\text { analysis or evaluation of } \\
\text { dynamic or emergent } \\
\text { properties }\end{array}$ \\
\hline $\begin{array}{l}\text { Fuzzy } \\
\text { cognitive } \\
\text { maps }\end{array}$ & $\begin{array}{l}\text { Medium to } \\
\text { High }\end{array}$ & $\begin{array}{l}\text { Concepts/system } \\
\text { components, structural } \\
\text { relationships between } \\
\text { concepts or components; } \\
\text { sign and strength of } \\
\text { causal influence between } \\
\text { concepts }\end{array}$ & $\begin{array}{l}\text { System structure } \\
\text { and system } \\
\text { states, sensitivity } \\
\text { for changes in } \\
\text { system structure }\end{array}$ & Neither & $\begin{array}{l}\text { Allows for feedbacks; } \\
\text { system components and } \\
\text { relationships easily added } \\
\text { or removed. Often intuitive } \\
\text { since based on concept } \\
\text { mapping; problem- } \\
\text { structuring with } \\
\text { stakeholders }\end{array}$ & $\begin{array}{l}\text { Model outputs not linked to } \\
\text { discrete values; nonlinear } \\
\text { relationships difficult } \\
\text { include; determining } \\
\text { consensus on components } \\
\text { and relationships takes time }\end{array}$ \\
\hline $\begin{array}{l}\text { Bayesian } \\
\text { belief } \\
\text { networks }\end{array}$ & $\begin{array}{l}\text { Medium to } \\
\text { High }\end{array}$ & $\begin{array}{l}\text { System components; } \\
\text { unidirectional } \\
\text { relationships between } \\
\text { components defined } \\
\text { based on probability } \\
\text { estimates }\end{array}$ & $\begin{array}{l}\text { Probabilistic or } \\
\text { conditional } \\
\text { system states }\end{array}$ & Neither & $\begin{array}{l}\text { Often intuitive since based } \\
\text { on concept mapping. Real- } \\
\text { world probabilities can be } \\
\text { assessed for model validity; } \\
\text { deals with uncertainty }\end{array}$ & $\begin{array}{l}\text { No feedbacks included; } \\
\text { determining consensus on } \\
\text { components and } \\
\text { probabilities may take time }\end{array}$ \\
\hline $\begin{array}{l}\text { Agent-based } \\
\text { models }\end{array}$ & Low & $\begin{array}{l}\text { Types of agents, rules of } \\
\text { behaviors for agents; } \\
\text { initial state conditions, } \\
\text { validation of the model }\end{array}$ & $\begin{array}{l}\text { Aggregate-level } \\
\text { system behavior, } \\
\text { system states }\end{array}$ & Both & $\begin{array}{l}\text { Allow for feedbacks; } \\
\text { model parameters easily } \\
\text { changed. Discrete units } \\
\text { that reflect real-world } \\
\text { values can be modeled; } \\
\text { handles non-linearity }\end{array}$ & $\begin{array}{l}\text { Agent types not easily } \\
\text { changed; not flexible in } \\
\text { participatory setting since } \\
\text { models are usually } \\
\text { constructed before } \\
\text { stakeholder workshops }\end{array}$ \\
\hline
\end{tabular}

and indeed "fuzzy" participatory approach that is most appropriate as a way to promote social learning and deliberation among diverse stakeholders and not as a formal assessment tool. The method would benefit from further development, including new analytical techniques, novel scenario algorithms that attempt to account for complexity, and additional empirical assessments that identify the social or ecological conditions that are more or less well suited for the use of FCM.

\section{Directions for future FCM research}

A number of directions regarding FCM should be explored in the future. Given the extent to which FCM allows for different kinds of information to be integrated into the same model, the process we describe can be used to gather multiple forms of evidence to validate perceived understanding through adaptive management. In the model-building process, not only do participants develop structural understanding of a complex system subjected to management, but through deliberation, they also discuss uncertainty. Such conversations can be used to suggest points for which further evidence is needed and can allow participants to determine what and how data can be collected to validate perceived dynamics empirically (Gray et al. 2014a). The notion of citizens participating as data collectors and decision makers is not new. However, because modern science is often seen as a solely expert-driven endeavor, lay individuals and more traditional knowledge forms often can be marginalized. Although some have argued that scientific reasoning is innate (Caruthers 2002), several examples of "citizen science" have yielded reliable evidence (e.g., Bonney et al. 2009, USA-based cases). We suggest that participatory modeling, specifically FCM, may extend the benefits of public participation in scientific research identified recently (Shirk et al. 2012). If deemed relevant, additional information in dynamically managed systems serves to directly improve model development as well as informed, direct resource management on the part of all stakeholders. Furthermore, the sensitivity of the scenarios to changes in the edge weights could be evaluated against the expectations of knowledge experts and stakeholders to correct or improve the FCM structure. However, to date, these appropriations of FCM are largely unexplored.

It is important to note that in participatory settings, FCMs are constructed based on perceived dynamics of a system; therefore, scenario analyses provide an understanding of perceived resilience measurements rather than empirical resilience measurements. However, we suggest that individuals can use specific data collection protocols validate not only the structural 
aspects of the model but also the model's predictions. Such interplay between the conjectured and the actual outcomes will allow for informed model refinement as well as provide a platform by which individuals can systematically test adaptive steps in the management process. In other words, as individuals ground-truth elements of their models, either by local measures or through available measures of greater spatial/temporal scope, they can test the underlying causal links between elements by running subsequent scenarios after new data/evidence forms are integrated.

Lastly, although comparisons between the preferred state, current steady state, and different scenario states provide useful benchmarks for discussion with stakeholders, determining conditions under which the system slips from one basin of attraction into another basin is not straightforward. Given the highly subjective nature of how the state space and preferred state are identified, whether the qualitative identity of an SES is maintained under scenarios is largely unclear and represents an area of research that would benefit from additional study. Based on our case study, when the steady-state condition was compared with the human population scenario, $40 \%$ of the components shifted from either positive or zero values to negative values independent of participant preference. This is an indication that the SES, given its current configuration, is perhaps not resilient to this particular type of disturbance; however, the importance of individual state-space variables was not determined and it is likely that some variables, e.g., wildebeest and zebra populations, likely contribute more to a system's identity than others. Further, when mitigation plans were added to the model, in some cases the values did change significantly, e.g., income and participation, which indicated that perhaps the management measures were more effective in adapting to a new regime and mitigating inevitable system responses, as opposed to building capacity within the system to maintain itself in its steady state. We suggest that researchers engaged in participatory modeling, resilience analysis, and FCM begin to develop new ways of measuring system identity. This may be accomplished by combining aspects of more qualitative approaches, i.e., narrative scenarios, with semiquantitative approaches iteratively, drawing on unique aspects of each in the participatory process.

\section{CONCLUSION}

The FCM approach described here has resulted in shared participation in management decision making. Not only do FCMs provide the opportunity to help stakeholders participate in management decisions, they can also facilitate the discourse with governing agencies, players in the management outcomes, and nonstakeholders seeking to understand the case. Because the process of developing an FCM requires understanding a few relatively lay terms and following simply logical heuristics, the resulting models tend to be transparent and, with explanation, can convey great meaning without cumbersome or jargon-laden text. Furthermore, because FCM allows for the integration of preferences and values, connections and outcomes can be judged relative to inputs. The latter can be favorable when disagreements about values and preferences halt discourse and negotiation. Finally, although more work using this approach is warranted, the possible benefits of using cognitive models to co-construct an explanatory model by which predictions and subsequent actions can be supported underscore the added value of FCM for bridging the gap between qualitative and quantitative approaches in participatory resilience assessment and ultimately resource management.

Responses to this article can be read online at: http://www.ecologyandsociety.org/issues/responses. $\mathrm{php} / 7396$

\section{Acknowledgments:}

We would like to thank CREATE (Conservation Research for East Africa's Threatened Ecosystem) who funded the case study presented in this research. CREATE is funded by FZS (Frankfurt Zoological Society) and the EU (European Union). Complimentary funding was provided by IFP (Ford Foundation International Fellowships Program). Additionally, we would like to thank the United States Department of Agriculture and the National Science Foundation for funding development of the Mental Modeler software. Lastly, we would like to thank the reviewers for constructive feedback that improved our manuscript.

\section{LITERATURE CITED}

Aalders, I. 2008. Modeling land-use decision behavior with Bayesian belief networks. Ecology and Society 13(1): 16. [online] URL: http://www.ecologyandsociety.org/vol13/iss1/art16/

Adger, W. N. 2000. Social and ecological resilience: are they related? Progress in Human Geography 24(3):347-364. http://dx. doi.org/10.1191/030913200701540465

Amer, M., A. Jetter, and T. Daim. 2011. Development of fuzzy cognitive map (FCM)-based scenarios for wind energy. International Journal of Energy Sector Management 5(4):564-584. http://dx.doi.org/10.1108/17506221111186378

Amici, V., F. Geri, and C. Battisti. 2010. An integrated method to create habitat suitability models for fragmented landscapes. Journal for Nature Conservation 18(3):215-223. http://dx.doi. org/10.1016/j.jnc.2009.10.002

Axelrod, R. 1976. Structure of decision: the cognitive map of political elites. Princeton University Press, Princeton, New Jersey, USA.

Benbenishty, R. 1992. An overview of methods to elicit and model expert clinical judgment and decision making. Social Service Review 66(4):598-616. http://dx.doi.org/10.1086/603950

Bennett, E. M., G. S. Cumming, and G. D. Peterson. 2005. A systems model approach to determining resilience surrogates for case studies. Ecosystems 8:945-957. http://dx.doi.org/10.1007/ $\underline{\text { 10021-005-0141-3 }}$

Bonney, R., H. Ballard, R. C. Jordan, E. McCallie, T. Phillips, J. Shirk, and C. C. Wilderman. 2009. Public participation in scientific research: defining the field and assessing its potential for informal science education. A CAISE Inquiry Group Report. Center for Advancement of Informal Science Education (CAISE), Washington, D.C., USA. [online] URL: http://www.informalscience. org/documents/PPSR \%20report\%20FINAL.pdf 
Brand, F. S., and K. Jax. 2007. Focusing the meaning(s) of resilience: resilience as a descriptive concept and a boundary object. Ecology and Society 12(1): 23. [online] URL: http://www. ecologyandsociety.org/vol12/iss1/art23/

Brooks, N. and W. N. Adger. 2004. Assessing and enhancing adaptive capacity. Pages 165-181 in B. Lim and E. SpangerSiegfried, editors. Adaptation policy frameworks for climate change: developing strategies, policies and measures. Cambridge University Press, Cambridge, UK. [online] URL: http://www. cakex.org/sites/default/files/ALL UNDP.pdf

Carpenter, S., B. Walker, J. M. Anderies, and N. Abel. 2001. From metaphor to measurement: resilience of what to what? Ecosystems 4:765-781. http://dx.doi.org/10.1007/s10021-001-0045-9

Carpenter, S. R., and W. A. Brock. 2008. Adaptive capacity and traps. Ecology and Society 13(2): 40. [online] URL: http://www. ecologyandsociety.org/vol13/iss2/art40/

Carpenter, S. R., W. A. Brock, and D. Ludwig. 2002. Collapse, learning and renewal. Pages 173-194 in L. H. Gunderson and C. S. Holling, editors. Panarchy: understanding transformations in human and natural systems. Island Press, Washington, D.C., USA.

Caruthers, P. 2002. The roots of scientific reasoning: infancy, modularity and the art of tracking. Pages 73-96 in P. Carruthers, S. Stich, and M. Siegal, editors. The cognitive basis of science. Cambridge University Press, Cambridge, UK. http://dx.doi. org/10.1017/CBO9780511613517.005

Craik, K. J. W. 1943. The nature of explanation. Cambridge University Press, Cambridge, UK.

Cumming, G., G. Barnes, S. Perz, M. Schmink, K. Sieving, J. Southworth, M. Binford, R. D. Holt, C. Stickler, and T. Van Holt. 2005. An exploratory framework for the empirical measurement of resilience. Ecosystems 8:975-987. http://dx.doi.org/10.1007/ $\underline{\mathrm{s} 10021-005-0129-\mathrm{Z}}$

Davidson, J. L., I. E. van Putten, P. Leith, M. Nursey-Bray, E. M. Madin, and N. J. Holbrook. 2013. Toward operationalizing resilience concepts in Australian marine sectors coping with climate change. Ecology and Society 18(3): 4. http://dx.doi. org/10.5751/ES-05607-180304

Estes, A. B., T. Kuemmerle, H. Kushnir, V. C. Radeloff, and H. H. Shugart. 2012. Land-cover change and human population trends in the Serengeti ecosystem from 1984-2003. Biological Conservation 147(1):255-263. http://dx.doi.org/10.1016/j. biocon.2012.01.010

Flavell, J. H. 1996. Piaget's legacy. Psychological Science 7 (4):200-203. http://dx.doi.org/10.1111/j.1467-9280.1996.tb00359. $\underline{x}$

Fletcher, C. S., M. Craig, and D.W. Hilbert. 2006. Operationalizing resilience in Australian and New Zealand agroecosystems. In Proceedings of the 50th Annual Meeting of the International Society for the Systems Sciences (ISSS). ISSS, Pocklington, UK. [online] URL: http://www.isssbrasil.usp.br/ isssbrasil/pdfs/2006-355.pdf

Folke, C. 2006. Resilience: the emergence of a perspective for social-ecological systems analyses. Global Environmental Change 16:253-267. http://dx.doi.org/10.1016/j.gloenvcha.2006.04.002
Fuentes, R. T. C. 2012. Qualitative mathematical modeling for resilience assessment and management [title translated from the Spanish]. Anales de la Academia de Ciencias de Cuba 2(1). [online] URL: http://www.revistaccuba.cu/index.php/acc/article/viewFile/111/931

Füssel, H.-M., and R. J. T. Klein. 2006. Climate change vulnerability assessments: an evolution of conceptual thinking. Climatic Change 75:301-329. http://dx.doi.org/10.1007/s10584-006-0329-3

Gallopín, G. C. 2006. Linkages between vulnerability, resilience, and adaptive capacity. Global Environmental Change 16:293-303. http://dx.doi.org/10.1016/j.gloenvcha.2006.02.004

Glykas, G., editor. 2010. Fuzzy cognitive maps: advances in theory, methodologies, tools and applications. Springer, Berlin, Germany. http://dx.doi.org/10.1007/978-3-642-03220-2

Gray, S., A. Chan, D. Clark, and R.C. Jordan. 2012. Modeling the integration of stakeholder knowledge in social-ecological system decision-making: benefits and limitations to knowledge diversity. Ecological Modelling 229:88-96. http://dx.doi. org/10.1016/j.ecolmodel.2011.09.011

Gray, S., D. Mellor, R. Jordan, A. Crall, and G. Newman. 2014a. Modeling with citizen scientists: Using community-based modeling tools to develop citizen science projects. In D. P. Ames, N. W. T. Quinn, and A. E. Rizzoli, editors. Proceedings of the 7th International Congress on Environmental Modelling and Software (iEMSs), June 15-19, San Diego, California, USA. iEMSs, Manno, Switzerland. ISBN: 978-88-9035-744-2. [online] URL: http://www.iemss.org/sites/iemss2014/papers/iemss2014 submission 153. pdf

Gray, S. A., S. Gray, L. J. Cox, and S. Henly-Shepard. 2013. Mental modeler: a fuzzy-logic cognitive mapping modeling tool for adaptive environmental management. Pages 963-973 in Proceedings of the 46th Hawaii International Conference on System Sciences (HICSS). HICSS, University of Hawaii at Manoa, Honolulu, Hawaii, USA. http://dx.doi.org/10.1109/ HICSS.2013.399

Gray, S. A., E. Zanre, and S. R. J. Gray. 2014b. Fuzzy cognitive maps as representations of mental models and group beliefs: theoretical and technical issues. Pages 29-48 in E. I. Papageorgiou, editor. Fuzzy cognitive maps for applied sciences and engineering - from fundamentals to extensions and learning algorithms. Springer, Heidelberg, Germany. http://dx.doi.org/10.1007/978-3-642-39739-4 2

Gray, S. R. J., A. S. Gagnon, S. A. Gray, B. O’Dwyer, C. O'Mahony, D. Muir, R. J. N. Devoy, M. Falaleeva, and J. Gault. 2014c. Are local coastal managers detecting the problem? Assessing stakeholder perception of climate vulnerability using Fuzzy Cognitive Mapping. Ocean \& Coastal Management 94:74-89. http://dx.doi.org/10.1016/j.ocecoaman.2013.11.008

Gunderson, L. 1999. Resilience, flexibility and adaptive management-antidotes for spurious certitude? Conservation Ecology 3(1): 7. [online] URL: http://www.consecol.org/vol3/iss1/ $\underline{\operatorname{art} 71}$

Gunderson, L. H., and C. S. Holling, editors. 2002. Panarchy: understanding transformations in human and natural systems. Island Press, Washington, D.C., USA. 
Halbrendt, J., S. A. Gray, S. Crow, T. Radovich, A. H. Kimura, and B. B. Tamang. 2014. Differences in farmer and expert beliefs and the perceived impacts of conservation agriculture. Global Environmental Change 28:50-62. http://dx.doi.org/10.1016/j. gloenvcha.2014.05.001

Harr, R. N., L. Wright Morton, S. R. Rusk, D. M. Engle, J. R. Miller, and D. Debinski. 2014. Landowners' perceptions of risk in grassland management: woody plant encroachment and prescribed fire. Ecology and Society 19(2): 41. http://dx.doi. org/10.5751/ES-06404-190241

Hobbs, B. F., S. A. Ludsin, R. L. Knight, P. A. Ryan, J. Biberhofer, and J. J. H. Ciborowski. 2002. Fuzzy cognitive mapping as a tool to define management objectives for complex ecosystems. Ecological Applications 12:1548-1565. http://dx.doi.org/10.1890/1051-0761 (2002)012[1548:FCMAAT]2.0.CO;2

Holling, C. S. 1973. Resilience and stability of ecological systems. Annual Review of Ecology and Systematics 4:1-23. http://dx.doi. org/10.1146/annurev.es.04.110173.000245

Holling, C. S., and G. K. Meffe. 1996. Command and control and the pathology of natural resource management. Conservation Biology 10(2):328-337. http://dx.doi.org/10.1046/

j.1523-1739.1996.10020328.x

Janssen, M. A., and E. Ostrom. 2006. Empirically based, agentbased models. Ecology and Society 11(2): 37. [online] URL: http:// www.ecologyandsociety.org/vol11/iss2/art37/

Jetter, A. J., and K. Kok. 2014. Fuzzy Cognitive Maps for futures studies - a methodological assessment of concepts and methods. Futures 61:45-57. http://dx.doi.org/10.1016/j.futures.2014.05.002

Jones, N. A., P. Perez, T. G. Measham, G. J. Kelly, P. D’Aquino, K. Daniell, A. Dray, and N. Ferrand. 2008. Evaluating participatory modeling: developing a framework for cross-case analysis. Socio-Economics and the Environment in Discussion (SEED). Working Paper Series Number 2008-11. CSIRO, Canberra, Australia.

Jones, N. A., H. Ross, T. Lynam, P. Perez, and A. Leitch. 2011. Mental models: an interdisciplinary synthesis of theory and methods. Ecology and Society 16(1): 46. [online] URL: http:// www.ecologyandsociety.org/vol16/iss1/art46/

Kafetzis, A., N. McRoberts, and I. Mouratiadou. 2010. Using fuzzy cognitive maps to support the analysis of stakeholders' views of water resource use and water quality policy. Pages 383-402 in M. Glykas, editor. Fuzzy cognitive maps: advances in theory, methodologies, tools and applications. Springer, Berlin, Germany. http://dx.doi.org/10.1007/978-3-642-03220-2 16

Kearney, J., F. Berkes, A. Charles, E. Pinkerton, and M. Wiber. 2007. The role of participatory governance and community-based management in integrated coastal and ocean management in Canada. Coastal Management 35:79-104. http://dx.doi. org/10.1080/10.1080/08920750600970511

Knapp, E. J. 2012. Why poaching pays: a summary of risks and benefits illegal hunters face in Western Serengeti, Tanzania. Tropical Conservation Science 4:434-445. [online] URL: http:// tropicalconservationscience.mongabay.com/content/v5/TCS-2012 Vol 5\% $\underline{284 \% 29 \quad 434-445 \quad \text { Knapp.pdf }}$
Kok, K. 2009. The potential of fuzzy cognitive maps for semiquantitative scenario development, with an example from Brazil. Global Environmental Change 19, 122-133. http://dx.doi. org/10.1016/j.gloenvcha.2008.08.003

Kosko, B. 1986. Fuzzy cognitive maps. International Journal of Man-Machine Studies 24:65-75. http://dx.doi.org/10.1016/ $\underline{\text { S0020-7373(86)80040-2 }}$

Kosko, B. 1994. Fuzzy thinking: the new science of fuzzy logic. Hyperion, New York, New York, USA.

Lerner, R. M., editor. 1998. Theoretical models of human development. Handbook of child psychology. Sixth edition. Volume 1. Wiley, New York, New York, USA.

Loiboki, M., H. Hofer, K. L. I. Campbell, and M. L. East. 2002. Bushmeat hunting by communities adjacent to the Serengeti National Park, Tanzania: the importance of livestock ownership and alternative sources of protein and income. Environmental Conservation 29:391-398. http://dx.doi.org/10.1017/S0376892902000279

Lynam, T., W. de Jong, D. Sheil, T. Kusumanto, and K. Evans. 2007. A review of tools for incorporating community knowledge, preferences, and values into decision making in natural resources management. Ecology and Society 12(1): 5. [online] URL: http:// www.ecologyandsociety.org/vol12/iss1/art5/

Mackinson, S. 2000. An adaptive fuzzy expert system for predicting structure, dynamics and distribution of herring shoals. Ecological Modelling 126(2-3):155-178. http://dx.doi.org/10.1016/ $\underline{\mathrm{S} 0304-3800(00) 00263-5}$

Meliadou, A., F. Santoro, M. R. Nader, M. A. Dagher, S. I. Indary, and B. A. Salloum. 2012. Prioritising coastal zone management issues through fuzzy cognitive mapping approach. Journal of Environmental Management 97:56-68. http://dx.doi.org/10.1016/ j.jenvman.2011.11.006

Mfunda, I. M., and E. Røskaft. 2010. Bushmeat hunting in Serengeti, Tanzania: an important economic activity to local people. Biodiversity and Conservation 2:263-272.

Murungweni, C., M. T. van Wijk, J. A. Andersson, E. M. A. Smaling, and K. E. Giller. 2011. Application of fuzzy cognitive mapping in livelihood vulnerability analysis. Ecology and Society 16(4): 8. http://dx.doi.org/10.5751/ES-04393-160408

Nayaki, A., S. A. Gray, C. A. Lepczyk, J. C. Skibins, and D. Rentsch. 2014. Local-scale dynamics and local drivers of bushmeat trade. Conservation Biology 28:1403-1414. http://dx. doi.org/10.1111/cobi.12316

Ndibalema. V. G., and A. N. Songorwa. 2008. Illegal meat hunting in serengeti: dynamics in consumption and preferences. African Journal of Ecology 46:311-319. http://dx.doi.org/10.1111/ j.1365-2028.2007.00836.x

Novak, J. D., and A. J. Cañas. 2008. The theory underlying concept maps and how to construct and use them. Technical Report IHMC CmapTools 2006-01 Rev 01-2008. Florida Institute for Human and Machine Cognition, Pensacola, Florida, USA. [online] URL: http://cmap.ihmc.us/publications/researchpapers/

theoryunderlyingconceptmaps.pdf

Ortolani, L., N. McRoberts, N. Dendoncker, and M. Rounsevell. 2010. Analysis of farmers' concepts of environmental 
management measures: an application of cognitive maps and cluster analysis in pursuit of modeling agents' behaviour. Pages 363-381 in M. Glykas, editor. Fuzzy cognitive maps: advances in theory, methodologies, tools and applications. Springer, Berlin, Germany. http://dx.doi.org/10.1007/978-3-642-03220-2 15

Özesmi, U., and S. L. Özesmi. 2004. Ecological models based on people's knowledge: a multi-step fuzzy cognitive mapping approach. Ecological Modelling 176:43-64. http://dx.doi. org/0.1016/j.ecolmodel.2003.10.027

Papageorgiou, E. I., and A. Kontogianni. 2012. Using fuzzy cognitive mapping in environmental decision making and management: a methodological primer and an application. Pages 427-450 in S. S. Young and S. E. Silvern, editors. International perspectives on global environmental change. InTech, Rijeka, Croatia. http://dx.doi.org/10.5772/29375

Papageorgiou, E. I., and J. L. Salmeron. 2013. A review of fuzzy cognitive maps research during the last decade. Fuzzy Systems, IEEE Transactions 21:66-79. http://dx.doi.org/10.1109/ TFUZZ.2012.2201727

Raskin, J. D. 2002. Constructivism in psychology: personal construct psychology, radical constructivism, and social constructionism. Pages 1-25 in J. D. Raskin and S. K. Bridges, editors. Studies in meaning: exploring constructivist psychology. Pace University Press, New York, New York, USA.

Rentsch, D. 2012. Bushmeat consumption and local demand for wildlife: wildebeest offtake estimates for Western Serengeti. Dissertation. University of Minnesota, Minneapolis and St. Paul, Minnesota, USA.

Ross, H., and F. Berkes. 2014. Research approaches for understanding, enhancing, and monitoring community resilience. Society \& Natural Resources 27(8):787-804. http://dx.doi. org/10.1080/08941920.2014.905668

Sandker, M., B. M. Campbell, M. Ruiz-Párez, J. A. Sayer, R. Cowling, H. Kassa, and A. T. Knight. 2010. The role of participatory modeling in landscape approaches to reconcile conservation and development. Ecology and Society 15(2): 13. [online] URL: http://www.ecologyandsociety.org/vol15/iss 2/ $\underline{\operatorname{art13/}}$

Schwarz, A.-M., C. Báná, G. Bennett, D. Boso, Z. Hilly, C. Paul, R. Posala, S. Sibiti, and N. Andrew. 2011. Vulnerability and resilience of remote rural communities to shocks and global changes: empirical analysis from Solomon Islands. Global Environmental Change 21:1128-1140. http://dx.doi.org/10.1016/j. gloenvcha.2011.04.011

Shirk, J. L., H. L. Ballard, C. C. Wilderman, T. Phillips, A. Wiggins, R. Jordan, E. McCallie, M. Minarchek, B. V. Lewenstein, M. E. Krasny, and R. Bonney. 2012. Public participation in scientific research: a framework for deliberate design. Ecology and Society 17(2): 29. http://dx.doi.org/10.5751/ ES-04705-170229

Swart, R. J., P. Raskin, and J. Robinson. 2004. The problem of the future: sustainability science and scenario analysis. Global Environmental Change 14:137-146. http://dx.doi.org/10.1016/j. gloenvcha.2003.10.002
United Nations Economic Commission for Europe (UNECE). 1998. Convention on access to information, public partipation in decision-making and access to justice in environmental matters. UNECE, Aarhus, Denmark. [online] URL: http://www.unece. org/fileadmin/DAM/env/pp/documents/cep43e.pdf

Voinov, A., and F. Bosquet 2010. Modeling with stakeholders. Environmental Modelling \& Software 25:1268-1281. http://dx.doi. org/10.1016/j.envsoft.2010.03.007

Walker, B., S. Carpenter, J. Anderies, N. Abel, G. S. Cumming, M. Janssen, L. Lebel, J. Norberg, G. D. Peterson, and R. Pritchard. 2002. Resilience management in social-ecological systems: a working hypothesis for a participatory approach. Conservation Ecology 6(1): 14. [online] URL: http://www. consecol.org/vol6/iss1/art14/

Walker, B., C. S. Holling, S. R. Carpenter, and A. Kinzig. 2004. Resilience, adaptability and transformability in social-ecological systems. Ecology and Society 9(2): 5. [online] URL: http://www. ecologyandsociety.org/vo19/iss2/art5/

Walters, C. 1986. Adaptive management of renewable resources. MacMillan, New York, New York, USA.

Walters, C. 1997. Challenges in adaptive management of riparian and coastal ecosystems. Conservation Ecology 1(2): 1. [online] URL: http://www.consecol.org/vol1/iss2/art1/

Wei, Z., L. Lui, and Z. Yanchun. 2008. Using fuzzy congnitive time maps for modeling and evaluating trust dynamics in the virtual enterprise. Expert Systems with Applications 35 (4):1583-1592.

Wildenberg, M., M. Bachhofer, M. Adamescu, G. De Blust, R. Diaz-Delgadod, K. G. Q. Isak, F. Skov, and V. Riku. 2010. Linking thoughts to flows - fuzzy cognitive mapping as tool for integrated landscape modelling. In Proceedings of the 2010 international conference on integrative landscape modelling —linking environmental, social and computer sciences, Montpellier, February 3-5. [online] URL: http://www.symposcience.org/exl-doc/colloque/ART-00002419. pdf

Wise, L., A. G. Murta, J. P. Carvalho, and M. Mesquita. 2012. Qualitative modeling of fishermen's behaviour in a pelagic fishery. Ecological Modeling 228(10):112-122. http://dx.doi.org/10.1016/ j.ecolmodel.2011.12.008 